\title{
Revisiting the relation between language and cognition:A Cross-cultural Study with odors
}

Christelle Chrea, Camille Ferdenzi, Dominique Valentin and Hervé Abdi

\section{(2) OpenEdition \\ 12 Journals}

Electronic version

URL: http://journals.openedition.org/cpl/2532

DOI: $10.4000 /$ cpl.2532

ISSN: $1379-6100$

Publisher

Centre PsyCLÉ

\section{Electronic reference}

Christelle Chrea, Camille Ferdenzi, Dominique Valentin and Hervé Abdi, « Revisiting the relation between language and cognition:A Cross-cultural Study with odors », Current psychology letters

[Online], 22, Vol. 2, 2007 | 2007, Online since 21 September 2007, connection on 08 September 2020 URL : http://journals.openedition.org/cpl/2532 ; DOI : https://doi.org/10.4000/cpl.2532

This text was automatically generated on 8 September 2020

(C) All rights reserved 


\title{
Revisiting the relation between language and cognition:A Cross- cultural Study with odors
}

\author{
Christelle Chrea, Camille Ferdenzi, Dominique Valentin and Hervé Abdi
}

Introduction

Compared to vision or audition, the sense of smell has been rather neglected by cognitive psychology research, maybe because olfaction was thought to be an emotional sense mostly playing a role in social interactions and approach-withdraw behaviors (Holley, 1999). But recently, the relation between olfaction and cognition has begun to attract more attention, especially the relation between olfaction and language (see, e.g., Ayabe-Kanamura et al., 1998; Herz \& von Clef, 2001; Richardson \& Zucco, 1989). This work suggests that linguistic information associated to odors is strongly dependent of cultural experience. For example, in a study examining the relation between familiarity, pleasantness and intensity for odors in two cultural groups, Ayabe-Kanumara et al. (1998) found that the odor of dried fish was described as "excrement" by German participants and as "edible food" by Japanese participants. These cross-cultural differences in odor label quality may reflect cross-cultural differences in familiarity with odors or more generally in cultural habits. Indeed dried fish is of daily consumption in Japan but not in Germany, and being less familiar to German participants, would be harder to identify. To further investigate the relation between culture and odor perception, some authors have wondered whether crosscultural differences found in odor naming and familiarity could have an influence on the way odors are categorized (Chrea et al., 2004; Ueno, 1993). Results showed that participants from different cultures seemed to agree upon the odor categories they used but also, at a finer level, there were some differences which may again be due to differences in familiarity and cultural habits. Thus it is reasonable to think that the cognitive processes underlying odor perception could be modulated by cultural experience, maybe through language associated to odors in a given culture. Indeed It has been already well established that the ability to name an odor influences the way it is perceived (Distel \& Hudson, 2001; Herz \& von Clef, 2001) and can influence its 
encoding and retrieval (see Herz \& Engen, 1996 and Larsson, 1997 for a review) The purpose of the present paper was to better understand the relation between linguistic information, odor representation and culture. In particular we were interested in evaluating if the relation that has been found for colors also holds for odors.

In an often cited cross-cultural study on colors, Lenneberg and Roberts (1953, in Brown \& Lenneberg, 1954) reported that Zuni Indian participants, who referred to orange and yellow with a single term, confused more frequently these two colors in a recognition task than English participants did. This result led Brown and Lenneberg (1954) to theorize that the number of available words for naming colors might influence memory for color. They named this effect the "codability effect." Codability in this context refers to the ease and degree of agreement with which people can name a referent. More generally, according to Brown and Lenneberg (1954), cognition, and especially memory, are affected by language via the codability of the items processed by the participants. Brown and Lenneberg hypothesized that a color of high codability was clearly defined and categorized, and was thus readily available because it was "nearer to the top of the cognitive deck" (p. 456). To test this hypothesis, Brown and Lenneberg (1954) measured the codability of 24 colors by asking a group of English participants to identify the colors twice, one month apart. For each color, the authors computed a series of codability indices including an interpersonal agreement index (level of consensus within a group of participants belonging to one culture) and an intrapersonal agreement index (consistency within each participant of this culture). Then, they asked an independent group of participants from the same culture to perform a recognition task on the same colors. They found that colors with a high interpersonal agreement score were memorized best. Later studies found similar results in cross-cultural studies (Heider, 1972; Kay \& Kempton, 1984; Roberson, Davidoff, \& Davies, 2000).

To follow the line of research applied to color representation, we investigated the relationship between codability and odor recognition memory cross-culturally. Curiously, only one published study directly investigated the influence of codability on odor memory (Lawless \& Cain, 1975). In contrast to studies using visual stimuli, Lawless and Cain did not find any relationship between odor codability and recognition memory. However, some empirical evidence supports the contention that codability may have some relevance in the cognitive processes involved in odor memory. For instance, associating a label to an odor improves its recognition (Walk \& Johns, 1984; Lyman \& McDaniel, 1986, 1990), and this improvement is greater when the label is repeatable (Rabin \& Cain, 1984; Lehrner, 1993; Sulmont, 2000) and precise (Engen \& Ross, 1973; Lesschaeve \& Issanchou, 1996). It therefore remains reasonable to expect codability to play a role in odor memory representation. We decided to use a cross cultural approach because we hypothesized that cultural comparisons were more likely to probe the relation between codability and a non linguistic behavior as it has been showed for colors that variability in codability across cultures gave rise to crosscultural differences in cognition (Kay \& Kempton, 1984; Roberson et al., 2000).

We carried out a study in American, French, and Vietnamese cultures because previous work with these three cultures showed that the consensus in odor naming depended upon the culture (Ly Mai, 2001). This study consisted in two experiments performed by two independent groups of participants in each culture. In Experiment 1, we evaluated the codability of 40 odorants, corresponding to everyday odors, in French, American, and Vietnamese cultural groups. A group of participants from each culture performed a 
double free identification task. We computed, from this double identification task, six codability indices that have been previously used in the visual domain. Three of these indices measured the agreement between participants of a given culture, and the three remaining indices measured the agreement within each participant. The aim of this first experiment was threefold. First, we intended to determine whether the notion of codability as defined for visual modalities was relevant in the olfactory modality. Second, we wanted to evaluate if the different indices tapped the same aspect of odor codability. Third, we wanted to verify that odor codability varies within and between the three cultural groups. In Experiment 2, we used the same 40 odorants as in Experiment 1, and we tested recognition memory with a standard yes/no recognition task performed by groups of participants from each of the three cultures. Our aim was to evaluate the existence of a link between these recognition data and the codability data obtained in Experiment 1 and to examine the consistency of this link between the three cultural groups.

EXPERIMENT 1: Odor codability measureMethodParticipants

Three groups of 19 students (see Table 1) were recruited from the University of Bourgogne at Dijon (France), the University of Texas at Dallas (United States), and the Polytechnic Institute at Danang (Vietnam). Participants did not have any previous experience with odor experiments. They were born and raised in the culture where the experiment took place. All participants were volunteers and none of them reported any problem with their sense of smell.

Table 1. Participants age and number (males, females) in Experiments 1 and 2

\begin{tabular}{|l|l|l|l|l|l|l|l|l|l|l|}
\hline & \multicolumn{2}{l|}{ France } & \multicolumn{2}{l|}{ The United States } & \multicolumn{2}{l|}{ Vietnam } \\
\hline \hline Experiment & $\mathrm{M}$ & $\mathrm{SD}$ & $\mathrm{N}(\mathrm{m} / \mathrm{f})$ & & $\mathrm{M}$ & $\mathrm{SD}$ & $\mathrm{N}(\mathrm{m} / \mathrm{f})$ & $\mathrm{M}$ & $\mathrm{SD}$ & $\mathrm{N}(\mathrm{m} / \mathrm{f})$ \\
\hline \hline Experiment 1 & 23.7 & 1.3 & $10 / 9$ & 24.3 & 4.7 & $4 / 15$ & 22.6 & 0.7 & $16 / 3$ \\
\hline \hline Experiment 2 & 22.8 & 3.9 & $7 / 13$ & 23.1 & 5.0 & $4 / 16$ & 22.4 & 1.2 & $9 / 11$ \\
\hline
\end{tabular}

Stimuli

Stimuli were 40 common odorants, manufactured by Sentosphère (Paris, France), and consisting of microencapsulated odorants contained in small punched flasks. The 40 stimuli were selected on the basis of cultural variability in familiarity rating and identificability among the French, American, and Vietnamese participants observed in a previous study (Ly Mai, 2001). The selected odorants (see Table 3) corresponded to edible / non edible and pleasant / unpleasant odors from every day life. A random 3digit number coded each odorant.

Procedure

Experiment 1 consisted of two identical identification tasks scheduled seven days apart. The experiment was run in a quiet room where one or two participants could take the test at once, in the presence of the experimenter. The 40 odorants were presented in a random order to participants who were instructed to smell each odorant and to try to identify it. Participants were given the following instructions: "Please try to use a single word if possible; if one word is not enough, you may use several words or a 
sentence. Please answer quickly and accurately. Avoid general terms." Participants' responses were recorded on a Macintosh running the Psyscope software (Cohen, McWhinney, Flatt, \& Provost, 1993). In the second session, odorant codes and presentation order differed from the first session. Moreover, participants were not told that the odorants were the same in both sessions.

To limit adaptation effects, participants were asked to breathe normally when smelling a sample and a 15-second inter-stimulus interval was set by the computer. Test procedures and instructions were identical in the three cultures, and instructions were given in the native language of the participants.

Results

As we found several ways to rate codability in the literature, we computed six different indices (see Table 2) based on previous studies on colors (Brown \& Lenneberg, 1954), pictures (Lachman, 1973) and odors (Lawless \& Cain, 1975). Three indices measured the interpersonal agreement during the first identification session (i.e., the consensus among participants in a given culture) and three indices measured the intrapersonal agreement between the first and the second identification session (i.e., the consistency within each participant). Indices were computed for each odor in each cultural group.

\begin{tabular}{|c|c|c|}
\hline Index & Measure and reference & Calculation procedure \\
\hline inter1 & $\begin{array}{l}\text { Interpersonal agreement } \\
\text { (Lawless \& Cain, 1975) }\end{array}$ & 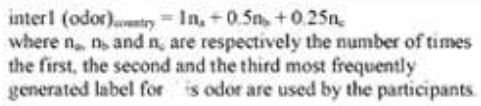 \\
\hline inter 2 & $\begin{array}{l}\text { Interpersonal agreement } \\
\text { (Brown \& Lenneberg. } \\
\text { 1954) }\end{array}$ & $\begin{array}{l}\text { inter } 2(O d o s)_{\text {andisy }}=\mathrm{CR}-\mathrm{DR}+20 \\
\text { where CR is the number of times the most frequently } \\
\text { generated label for this odor is wsed by the participants, } \\
\text { where DR is the number of different labels generated by } \\
\text { the participants for this odor and where } 20 \text { is arbitrarily } \\
\text { chosen to keep the results positive. }\end{array}$ \\
\hline inter 3 & $\begin{array}{l}\text { Interpersonal agreement } \\
\text { (Lachman, 1973) }\end{array}$ & 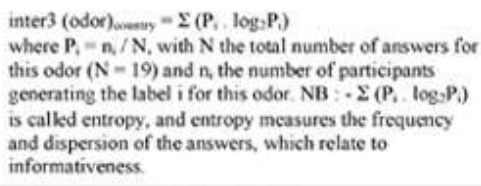 \\
\hline intral & $\begin{array}{l}\text { Intrapersonal agreement } \\
\text { (Lawless \& Cain, 1975) }\end{array}$ & $\begin{array}{l}\text { intral (odor) })=\Sigma\left(1 / S_{x}+1 / 2 S_{x} \text { ) }\right. \\
\text { where } S_{x} \text { and } S_{x} \text { are the sum of repeatable of partially } \\
\text { fepeatable labels given by the participants } x \text { and } x^{\prime} \\
\text { between the first and the second identification session } \\
\text { (global participant's performance), participant } x \text { having } \\
\text { labeled this odor with a repeatable name and participant } \\
x^{\prime} \text { having labeled this odor with a partially tepeatable } \\
\text { name. }\end{array}$ \\
\hline intra 2 & $\begin{array}{l}\text { Intrapersonal agreement } \\
\text { (Brown \& Lennelerg. } \\
\text { 1954) }\end{array}$ & 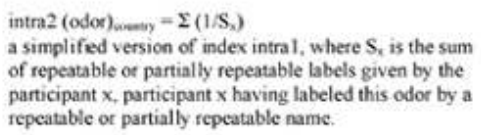 \\
\hline intra 3 & Intrapersonal agreement & $\begin{array}{l}\text { intra } 3 \text { (odor) })_{\text {nanasy }}=\Sigma \mathrm{P} \text {, } \\
\text { where } \mathrm{P}=1,0.5 \text { or } 0 \text { if participant } x \text { has labeled this } \\
\text { odor respectively with a repeatable, a partially repeatable } \\
\text { of a not repeatable name. }\end{array}$ \\
\hline
\end{tabular}

Equivalence of the indices

To evaluate the relation between the six different indices, we performed a principal component analysis (PCA) of these six indices for each cultural group (see Fig. 1). The data table was organized as a matrix where odors were in row and the six indices in column and where the intersection between a row $i$ and a column $j$ was the value of the index $j$ for the odor $i$. In all cases, the first factor of the PCA extracted a major proportion of variance $(89 \%, 87 \%$, and $91 \%$ respectively for the French, the American, and the Vietnamese group). The six indices loaded strongly and positively on this first factor. Factor 2 opposed inter- and intrapersonal agreement indices, but accounted only for a small percentage of variance $(9 \%, 11 \%$, and $5 \%$ respectively for the French, 
the American, and the Vietnamese groups) and was associated with an eigenvalue smaller than one, so we concluded that the distinction between inter- and intrapersonal agreement indices was negligible. Therefore, we used Factor 1, which is the best linear combination of the six indices, as a single codability measure in the remaining of this paper. Specifically, we used the first factor score of each odor as its codability score (see Table 3 for codability scores and most frequently used labels attributed to the 40 odors in each cultural group).

Figure 1: Indices of interpersonal agreement (inter1, inter2 and inter3) and intrapersonal agreement (intra1, intra2 and intra3) represented on the first factorial space of the principal component analyses (PCA) computed for France, the United States and Vietnam.
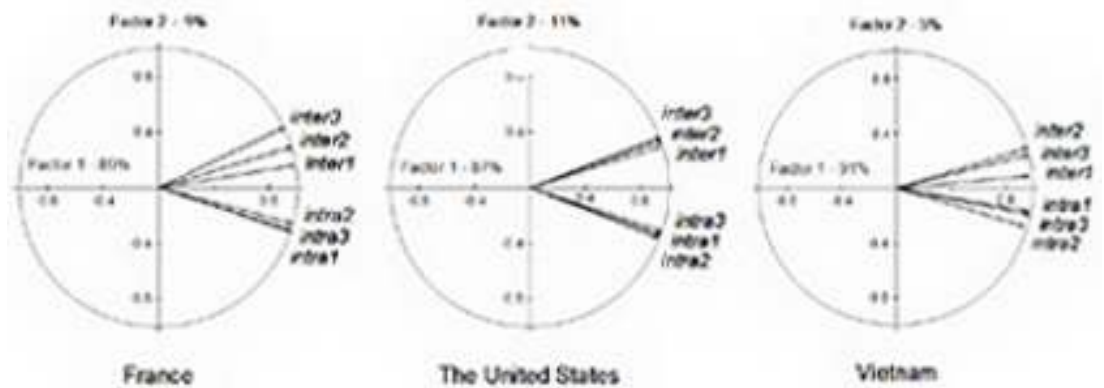

\begin{tabular}{|c|c|c|c|c|c|c|}
\hline \multirow[b]{2}{*}{ odst } & \multicolumn{2}{|c|}{ France } & \multicolumn{2}{|c|}{ The United States } & \multicolumn{2}{|c|}{ Vetnam } \\
\hline & Coda. & Labet & $\operatorname{cod} n$. & Lated & coda. & Labet \\
\hline anive & 5.92 & reglisse (licorice) & 5.01 & licorice & 0.71 & kno (tandy) \\
\hline blackeurrant & .0 .19 & bonbon (candy) & -297 & cherry & -1.92 & $k=0$ (candy) \\
\hline butter & -1.40 & tromage (cheese) & 106 & cheese & .222 & . \\
\hline cotpee ${ }^{\circ}$ & .406 & . & 0.16 & booy coder & -1.40 & banh (cake) \\
\hline chocolate & 2.13 & cacoo (Cocoa) & 5.03 & chocolate & 1.07 & $\cos a 0^{\circ}(\cos 0 \theta)$ \\
\hline cinnamon' & 1.88 & cannele (cinnamon) & 7.80 & cinnamon & 12.60 & que (cinnamon) \\
\hline civet & .323 & . & .290 & flower & $-1,33$ & hoa (tower) \\
\hline dove & 1.40 & clou de girote (clove) & .0 .42 & cloves & -1.00 & hea hol (anize) \\
\hline cosconit & .0 .86 & noix de cose (cosconvi) & 258 & cosonut & 0.89 & banh (cake) \\
\hline coobies & 153 & vanile (vanil) & 232 & vanila & -1.17 & keo (c) \\
\hline eucalyphus" & 0.72 & eucalypars (eucas & .176 & eucayptus & 237 & dov (oil) \\
\hline gavie & 5.89 & ail (garik) & 4.31 & gartic & 1.94 & toil (omalic) \\
\hline ginger & -138 & citron (lemon) & -0.15 & ginget & 3.31 & ging (gingen) \\
\hline hazethut & -172 & amande (almons) & -170 & hazehut & .130 & keo (cancy) \\
\hline heney & -1.50 & mid (honey) & -252 & honey & .0 .66 & mut ong (homey) \\
\hline jasmine & .222 & Seur (Sowere) & .236 & joamine & 0.26 & hoa nhai (jasmine) \\
\hline lavender & 4.89 & lavande (lovender) & .380 & lavender & .0 .84 & dev (oil) \\
\hline leather & .373 & amande (almond) & 224 & leather & -230 & . \\
\hline Wy of the valtey & 128 & muguet (by of the valley) & -121 & soap & 4.78 & hos nhai (josmine) \\
\hline mango" & .380 & . & .402 & lemon & -2.09 & keo (ca \\
\hline meton & 298 & melon (meion) & 160 & watermelon & -1.01 & keo (candy) \\
\hline $\min t$ & 438 & menthe (mint) & 288 & $\operatorname{mint}$ & 3.77 & bacha (mint) \\
\hline moloy & .052 & champignon (muahroom) & +183 & dint & .023 & moc (moldy) \\
\hline moerba & .381 & . & -1.45 & dean & .0 .39 & thwor (insecticide) \\
\hline mustroom & 2.17 & champignon (must) & .302 & mushrooms & 0.50 & $\operatorname{mos}($ moldoy) \\
\hline crange blossom" & .0 .05 & teur foranger (orange & .325 & flowers & .0 .78 & hoa nhai (jasmine) \\
\hline pesent. & -3003 & cacahuste (peanut) & -1.06 & peanut & -2.14 & $=$ \\
\hline peppet & 367 & Doivre (eepper) & 405 & peppes & .241 & seu (peppen) \\
\hline pine & -231 & tomarin (rosemary) & -1.39 & pine & .222 & dov (oil) \\
\hline pineapple & 292 & ananas (pineapple) & 1.31 & pineapple & -1.94 & trai (sour) \\
\hline rose & 0.04 & rose 600 & 274 & rose & -2.05 & keo (candy) \\
\hline sow & 190 & savon (roap) & 220 & sose & .0 .74 & xa beng (bath get) \\
\hline stramberry & 325 & taise (stawbery) & -107 & stramberry & 0.15 & keo (candy) \\
\hline tea & -293 & poivre & -3.78 & tea & -0.78 & hoa nhai (jasmine) \\
\hline trut & .152 & tomage (c) & 000 & chea. & $-1,38$ & banh (cake) \\
\hline vanelas & 164 & vanile (vanilta) & 136 & vanith & .190 & kno (dy odon) \\
\hline volet & .250 & violette (violet) & .225 & powder & -1.46 & keo (canoy) \\
\hline wain & .1 .33 & & -102 & wahuts & 0.10 & thuoc (insect \\
\hline winte & .232 & camphre (camphor) & .095 & spearmint & 5.29 & dau (oil) \\
\hline woody & .4 .10 & bois (mood) & -1.71 & dint & .203 & $\infty 0$ (พ⿻00) \\
\hline
\end{tabular}

a Coda.: codability value (the three highest codability values and the associated most frequently used label are in bold type)

* Odors chosen as targets in Experiment

Codability within and between cultural groups

The codability scores (gathered in Table 3) show that, as we expected, the consensus for an odor label varied as a function of the odors both within and between cultures. 
Codability within a cultural group. Distributions of the codability scores were examined across the French, American, and Vietnamese groups for the whole set of odorants (see Fig. 2). Clear differences appear between these distributions. Whereas the French distribution seems bimodal, the American and Vietnamese distributions are positively skewed (skew coefficients 0.73 , and 2.67 for American and Vietnamese distributions respectively). This indicates that, for the American and even more so for the Vietnamese group, codability scores were concentrated on the lower part of the codability dimension. However in all three cultures, some odors received high codability scores (France: anise: 5.92, garlic: 5.89, lavender: 4.89; the United States: cinnamon: 7.80 , chocolate: 5.03 , anise: 5.01 ; Vietnam: cinnamon: 12.6 , wintergreen: 5.29 , and lily of the valley: 4.78$)$.

A large discrepancy between the three cultural groups emerged also in the general shape of the distributions and this was reflected by large differences in kurtosis coefficients. While the French kurtosis coefficient was slightly negative $(-0.81)$, the American one was almost null (0.03) and the Vietnamese one was highly positive (9.41). This indicates that codability scores were clearly spread out in the French group and to a lesser extent in the American group but not in the Vietnamese group.

Figure 2: Distribution of the codability scores for French, American and Vietnamese cultures
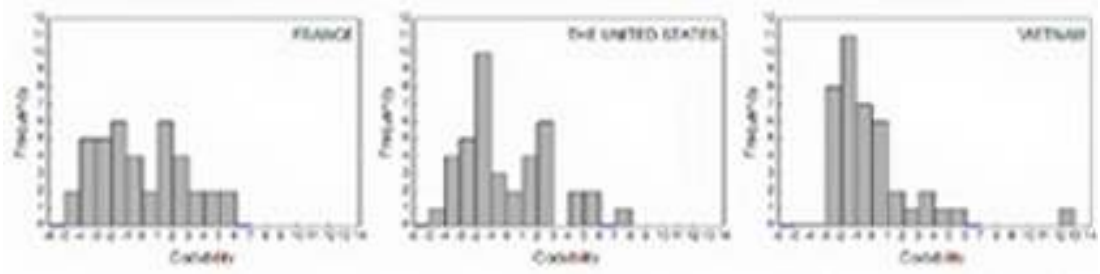

Codability between the cultural groups. Although some odors received high codability scores (e.g., mint, garlic) or low codability scores in the three cultural groups (e.g., violet, mango), two-third of the odors were highly codable in only one or two cultural groups (e.g., lavender was codable only in the French group, leather only in the American group, wintergreen only in the Vietnamese group). The analysis of the most frequently used labels, also revealed qualitative variations. Some odors were named identically in the three cultures (e.g., mint, cinnamon) but some other odors were labeled differently. For instance, melon was labeled consensually "melon" in France and "watermelon" in the United States, and lily of the valley was labeled consensually "lily of the valley" in France and "jasmine" in Vietnam.

Discussion

Our results indicate that the six different indices taken from the literature are roughly equivalent: All these indices express a common dimension represented by the first component of the PCA. This dimension reflects the consensus (both within a culture and within each member of this culture) of the association between an odor and a label. The notion of codability thus seems to be applicable to odors even though, unlike colors, there is no specific vocabulary that has been extracted to describe odors.

Additionally, our results show that codability depends on culture both at a quantitative and a qualitative level. At a quantitative level, we found that codability was globally lower in Vietnam than in the two other cultures. Two non exclusive explanations may be put forward for this effect. The first explanation is linked to a particularity of the Vietnamese language, which possesses accessory terms to express hedonic and 
intensity nuances when referring to odors (Tung \& Krowolski, 1998). These accessory terms were frequently added to the odor labels in our study, but not in a consistent way within and between participants. The inconsistent use of accessory terms might have contributed to the general low codability scores for the Vietnamese group. The second explanation is linked to the familiarity of the odors. Although we made sure to include odors encountered in Vietnam in the set of odorants, our odorants were manufactured in France and were probably closer to familiar odors present in western countries. During the identification task, Vietnamese participants often used general terms (e.g., candy, cake, oil, or flower, see Table 3) suggesting that they had some difficulties to identify the odors compared to French and American participants.

At a qualitative level, we found that about two-thirds of the odorants appeared to be of high codability in only one or two cultures and that odor label quality differed across the three cultures. This result is consistent with previous work with these three cultures (Ly Mai, 2001) and also with cross-cultural studies which found a large effect of culture on odor label quality (Aubaile Sallenave, 2000; Ayabe-Kanamura et al., 1998; Doty et al., 1985; Pangborn, Guinard, \& Davis, 1988; Wysocki, Pierce, \& Gilbert, 1991). These cross-cultural differences may again reflect cross-cultural differences in the frequency of exposure to specific odors. In agreement with this interpretation, some data collected from a questionnaire in the French, American, and Vietnamese populations (Chrea, 2005) showed a link between the frequency of encounter of odorant objects and performance on an identification task. Odorant objects that are often encountered in a given culture are more likely to be consensually used to identify an odor.

To summarize, this first experiment showed that codability defined as the consensus in odor labeling is a notion that can be applied to the olfactory modality and that various indices from the literature are concordant to measure this consensus. Moreover, codability of the 40 stimuli was clearly prone to cross-cultural variations. These variations in turn make it possible to investigate (in Experiment 2) the link between codability and odor recognition memory, and its stability across the three cultures.

EXPERIMENT 2: Odor codability and recognition memoryMethodParticipants

A total of 59 students (see Table 1) were recruited in the French, American, and Vietnamese universities mentioned in Experiment 1. All participants were born and raised in the culture where the experiment took place. They had not taken part in Experiment 1 and did not have previous experience with odor experiments. None of them reported to have any problem with their sense of smell.

Stimuli

Stimuli were the same 40 odorants used in Experiment 1, divided in a group of 20 targets and a group of 20 distractors (see Table 3). As our aim was to determine whether codability could predict recognition of odors, the main criterion for the constitution of the target group was the codability score of the odors. We thus selected 20 odors which included 1) odors with a high codability score in all three cultures, 2) odors with a low codability score in all three cultures, and 3) odors with a high codability score in only one or two cultures. A secondary criterion of interest was to balance the groups of targets and distractors in terms of pleasantness and perceptual similarity. Both variables were assessed in a previous study on similar French, American, and Vietnamese populations where participants rated pleasantness on a 7- 
point rating scale, and similarity was determined by means of a free sorting task (Chrea et al., 2004).

Procedure

The recognition task consisted in two sessions-one learning and one testing sessionsscheduled seven days apart. In the first session, participants were asked to smell each of the 20 target odorants and try to memorize them in order to recognize them during the second session of the task. They were given the following instructions: "Concentrate on the odor you just smelled and try to memorize it." The second session consisted in presenting to the participants the set of 40 odorants. This set was composed of the 20 target odorants and the 20 distracting odorants. Participants had to smell each odorant and answer "yes" or "no" to the question: "Did you smell this odor during the first session of this test?"

Results

As we were interested in the effect of codability on recognition memory, we analyzed only the correct recognition for target odorants ${ }^{1}$ (hit rate). We first examined the potential predictive role of codability on recognition memory within each cultural group and then cross-culturally.

Prediction of recognition memory by codability within a cultural group

Linear regression analyses were performed in each cultural group on the 20 target odors. The independent variable was the codability of the target odors, determined as the score of the odors on the first factor of the PCA carried out in Experiment 1. The dependent variable was the hit rate. Regressions between codability and hit rate (see Fig. 3) were significant in the French group ( $\left.F 1,18=4.72, p<0.05, R^{2}=0.21\right)$, but were not significant in the American and in the Vietnamese group.

To evaluate if the previous results could be due to differences in recognition performances between the three cultural groups, we performed an ANOVA with culture as the independent variable and hit rate as the dependent variable. The ANOVA revealed a significant effect of culture, $F 2,18=3.2, p<0.05$. A Duncan test (significance level: 0.05$)$ showed that the hit rate in the American group $(\mathrm{M}=71.8, \mathrm{SD}=2.6)$ was significantly higher than in the Vietnamese group $(\mathrm{M}=63.4, \mathrm{SD}=2.8)$. No significant difference was found between the French group $(\mathrm{M}=66.8, \mathrm{SD}=2.1)$ and each of the two other groups.

Figure 3: Linear regressions between codability and hit rate by odor. Results are presented for the 20 target odors in France (A) and the United States (B), for 19 target odors (without cinnamon, dot in brackets) in Vietnam (C). ns: not significant, $* p<0.05$. 


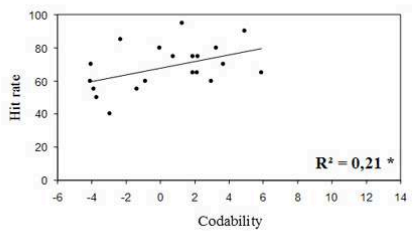

B. The United States

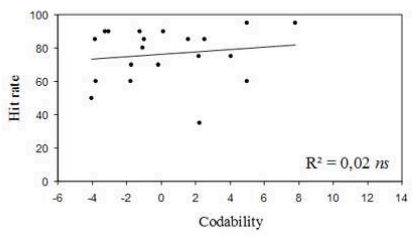

C. Vietnam

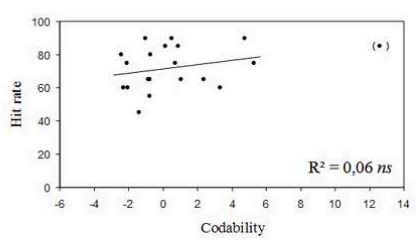

Cross-cultural prediction of recognition memory by codability

To evaluate whether the prediction of memory by codability was culture-dependent, we performed linear regressions between codability of each culture and hit rates of the two other cultures. The results showed that American and Vietnamese codability respectively did not predict hit rates in the other cultures. However, we found that codability in the French group predicted hit rates in both the American and Vietnamese groups $\left(F 1,18=5.67, p<0.05, R^{2}=0.24\right.$, and $F 1,18=7.68, p<0.05, R^{2}=0.30$ respectively).

Discussion

Our results suggest that codability can predict recognition memory for odors in one of the three cultural groups, namely the French group. This result supports the existence of a relation between linguistic information and non linguistic behavior at least in the French group. In order to compare our results with results for colors, Spearman rankorder correlation were computed between codability scores and hit rates. The results obtained in our French group $(r=0.43)$ were comparable to those obtained in previous studies on color memory ( $r=0.41$ in Brown \& Lenneberg, 1954, and 0.56 in Srivastava, 1977). Thus, in contrast to the previous study by Lawless and Cain (1975), codability seems to be an influential factor in the memorization process of chemosensory stimuli to the same extent as it is for other sensory modalities. The remaining question now is: Why did codability predict recognition memory in France but not in the United States or in Vietnam? Our results indicate that, although discrepancies in recognition performance emerged between the three cultures, the level of recognition did not seem to interact in the relationship between codability and recognition memory. Indeed the link between codability and recognition memory was observed only in the French group which elicited recognition performance intermediary between the American and the Vietnamese groups. If the link between codability and recognition memory implied superiority in recognition abilities, we should have found higher recognition 
performance in the French group. A more plausible explanation is linked to the distribution of the codability scores in the three cultural groups. Indeed, codability scores were more distributed in France than in the two other cultural groups, and because a larger spread allowed for a better prediction, this may explain that the link between codability and recognition memory was observed only in the French group.

General discussion

In the present experiment, we investigated the role of codability in odor memory in three cultures: French, American, and Vietnamese. Our first objective was to evaluate whether codability was a meaningful dimension to understand the cognitive processes involved in odor memory representations. For that purpose we evaluated the relevance and the consistency of several indices that were used to measure codability of visual stimuli. In Experiment 1, we showed that codability measured by both inter- and intrapersonal agreement indices has some relevance for odors. Moreover, we found agreement in the different indices we measured and this agreement reflects the validity of the codability construct. Finally, as expected, we found that the codability of an odor was partially dependent on the culture. Our second objective in Experiment 2 was to evaluate the extent to which codability could predict a non-linguistic behavior such as odor recognition memory. We found that the French codability scores predicted recognition memory performance in all three cultures. By contrast, the American and Vietnamese codability scores predicted none of the recognition performances. The remaining question is to know what could be the mechanisms underlying the odor codability effect?

To address this issue, we can use the color modality as the most documented model to interpret codability. Indeed, research on color codability has given rise to two opposing views: (1) a cultural relativist view suggesting that color perception is greatly shaped by culturally-specific language and that the language we grew up learning and speaking directs and constrains the way we perceive and organize information about the world (Whorf, 1956, in Kay \& Kempton, 1984) and (2) an universalist view suggesting that color perception is driven by neurophysiological color vision processing as the basis for color salience and naming coherence within and across cultures (Berlin \& Kay, 1969; Heider, 1972). These two opposed views are still debated, as demonstrated by the impressive number of papers investigating color naming and categorical perception in different cultures (see e.g., Davidoff, 2001; Hardin \& Maffi, 1997; Kay \& Regier, 2006).

If we try to bring this debate in the olfactory domain, our results seem to be more in agreement with the second view than with the first one. Indeed, we found that French codability not only predicted the French odor recognition memory but that it also predicted recognition memory for the other two cultural groups. A plausible interpretation is that the codability effect we observed is not due to the properties of language, but to perceptual properties of the odors themselves. In fact, as was suggested by Heider (1972) to account for universals in color naming and color categorization, it is possible that odor codability is determined by the perceptual salience of odors. To explain the cultural differences we found, we can imagine that odors which were consensually labeled in France were also perceptually salient in the three cultural groups. And because the odors were manufactured in France and thus were probably more familiar to French participants, these latter participants were better able to pin down their perceptual salience in words, regardless the correctness of the names, than participants from the two other groups. This interpretation suggests that some universal invariants might exist in odor representation. In agreement with 
this idea, Chrea et al. (2005) found that participants from the same three cultures tended to agree on how they categorize typical odors from every day life but tended to disagree for less typical odors. The next question would be then: Why are some odors perceptually more salient than others? A possibility is that odor salience has a physiological origin as it was suggested for color salience (Heider, 1972). Recent work on odor-structure relationships suggests that some receptors may be more selective than others and may respond to a specific class of odorant substances (e.g. Laing, Legha, Jinks, \& Hutchinson, 2003). It is tempting to speculate, as suggested by Holley (2001), that the odors to which these high selectivity receptors are preferentially tuned, might be more salient and thus would be both codable and well-recognized.

However, we can wonder to what extent odor salience is comparable to color salience. According to the universalist view, color salience influences the formation and the coherence of linguistic categories across cultures. This is unlikely to appear for odors because odor codability refers to the consensus in a concrete name of a unique odorant object and not to the consensus in an abstract name of a linguistic category as for colors. A factor that may be of higher relevance for odors is the functional context in which odors are encountered. Indeed, it has been empirically reported that, what Dubois (1997) calls "pragmatic factors of human activities" (e.g., hunting, cooking, domestic life, body odors), influence how odors are represented in memory in different cultures (Aubaile Sallenave, 2000; Chrea et al., 2004; Dubois, 2000). For example, the same odor of wintergreen can be associated to a candy by Americans or to a traditional medicine by Vietnamese (Chrea et al., 2004). Therefore, if we give sense to these odorspecific factors, what would drive the organization of odors in memory is not the name itself, as for colors, but the function linked to the odorant source. Codability would thus measure in this context the consensus in the function associated to the odor rather than in the name itself.

Acknowledgements

The authors would like to thank Bruno Patris and Thanh Bao for their help in collecting the data, and Dung Hoang Nguyen, Betty Edelman, and Nick Furl for their help in the analysis of the identification data.

\section{BIBLIOGRAPHY}

Aubaile Sallenave, F. (2000). Odeurs en alimentation dans quelques sociétés de Méditerranée : premiers résultats d'une enquête sur perception et reconnaissance. Bulletins et Mémoires de la Société d'Anthropologie de Paris, 12, 373-395.

Ayabe-Kanamura, S., Schicker, I., Laska, M., Hudson, R., Distel, H., Kobayakawa, T., \& Saito, S. (1998). Differences in perception of everyday odors: a Japanese-German cross-cultural study. Chemical senses, 23, 31-38.

Berlin, B., \& Kay, P. (1969). Basic Color Terms: their Universality and Evolution. Berkeley: University of California Press. 
Brown, R. W., \& Lenneberg, E. H. (1954). A study in language and cognition. Journal of Abnormal and Social Psychology, 49, 454-462.

Chrea, C. (2005). Odeurs et catégorisation : A la recherche d'universaux olfactifs. Thèse de doctorat, Université de Bourgogne, Dijon.

Chrea, C., Valentin, D., Sulmont-Rossé, C., Mai, H. L., Nguyen, D. H., \& Abdi, H. (2004). Culture and odor categorization: agreement between cultures depends upon the odors. Food Quality and Preference, 15, 669-679.

Chrea, C., Valentin, D., Sulmont-Rossé, C., Nguyen, D. H., \& Abdi, H. (2005). Semantic, typicality and odor representation: A cross-cultural study. Chemical Senses, 30, 37-49.

Cohen, J. D., McWhinney, B., Flatt, M., \& Provost, J. (1993). PsyScope: a new graphic interactive environment for designing psychology experiments. Behavior Research Methods Instruments \& Computers, 25, 257-271.

Davidoff, J. (2001). Language and perceptual categorisation. Trends in Cognitive Sciences, 5(9), 382-387.

Distel, H., \& Hudson, R. (2001). Judgement of odor intensity is influenced by subjects' knowledge of the odor source. Chemical Senses, 26, 247-251.

Doty, R. L., Applebaum, S., Zusho, H., \& Settle, R. G. (1985). Sex differences in odor identification ability: a cross-cultural analysis. Neuropsychologia, 23, 667-672.

Dubois, D. (1997). Cultural beliefs as nontrivial constraints on categorization: Evidence from colors and odors. Behavioral and Brain Sciences, 20, 188.

Dubois, D. (2000). Categories as acts of meaning: The case of categories in olfaction and audition. Cognitive Science Quarterly, 1, 35-68.

Engen, T., \& Ross, B. M. (1973). Long-term memory of odors with and without verbal descriptions. Journal of Experimental Psychology, 100, 221-227.

Hardin, C. L., \& Maffi, L. (Eds.) (1997). Color categories in thought and language. Cambridge: University Press.

Heider, E. R. (1972). Universals in color naming and memory. Journal of Experimental Psychology, 93, 10-20.

Herz, R. S., \& von Clef, J. (2001). The influence of verbal labeling on the perception of odors: evidence for olfactory illusions? Perception, 30(3), 381-391.

Herz, R. S., \& Engen, T. (1996). Odor memory: Review and analysis. Psychonomic Bulletin \& Review, 3(3), 300-313.

Holley, A. (1999). Eloge de l'odorat. Paris: Odile Jacob.

Holley, A. (2001). From Stimulus perception to category formation in chemical senses. Paper presented at the 4th Pangborn Sensory Science Symposium, Dijon, France.

Kay, P., \& Kempton, W. (1984). What is the Sapir-Whorf hypothesis? American Anthropologist, 86, 65-79.

Kay, P., \& Regier, T. (2006). Language, thought and color: recent developments. Trends in Cognitive Sciences, 10(2), 51-54.

Lachman, R. (1973) Uncertainty effects on time to access the internal lexicon. Journal of Experimental Psychology, 99, 199-208. 
Laing, D. G., Legha, P. K., Jinks, A. L., \& Hutchinson, I. (2003). Relationship between molecular structure, concentration and odor qualities of oxygenated aliphatic molecules. Chemical Senses, 28, 57-69.

Larsson, M. (1997). Semantic Factors in Episodic Recognition of Common Odors in Early and Late Adulthood: A Review. Chemical Senses, 22, 623-633.

Lawless, H. T., \& Cain, W. S. (1975). Recognition memory for odors. Chemical Senses and Flavor, 1, 331-337.

Lehrner, J. P. (1993). Gender differences in long-term odor recognition memory: verbal versus sensory influences and the consistency of label use. Chemical Senses, 18, 17-26.

Lenneberg, E. H., \& Roberts, J. M. (1953). The denotata of color terms. Paper presented at the Linguistic Society of America, Bloomington, Indiana.

Lesschaeve, I., \& Issanchou, S. (1996). Effects of panel experience on olfactory memory performance: influence of stimuli familiarity and labeling ability of subjects. Chemical senses, 21, 699-709.

Ly May, H. (2001). Effet de la culture sur la perception, l'identification et l'appréciation des odeurs. Mémoire de Diplôme Supérieur d'Etudes et de Recherche, Université de Bourgogne, Dijon.

Lyman, B. J., \& McDaniel, M. A. (1986). Effects of encoding strategy on long-term memory for odors. Quarterly Journal of Experimental Psychology, 38, 753-765.

Lyman, B. J., \& McDaniel, M. A. (1990). Memory of odors and odor names: modalities of elaboration and imagery. Journal of Experimental Psychology: Learning, Memory, and Cognition, 16, 656-664.

Pangborn, R. M., Guinard, J.-X., \& Davis, R. G. (1988). Regional aroma preferences. Food Quality and Preference, 1, 11-19.

Rabin, M. D., \& Cain, W. S. (1984). Odor recognition: familiarity, identifiability, and encoding consistency. Journal of Experimental Psychology: Learning, Memory, and Cognition, 10, 316-325.

Richardson, J. T. E., \& Zucco, G. M. (1989). Cognition and Olfaction: A Review. Psychological Bulletin, 105(3), 352-360.

Roberson, D., Davidoff, J., \& Davies, I. (2000). Color categories are not universal: Replication and new evidence from a stone-age culture. Journal of Experimental Psychology: General, 129, 369-398.

Srivastava, S. (1977). Codability, recognition and discrimination of colors among under graduate collegiate girls. Psycho-lingua, 7, 41-46.

Sulmont, C. (2000). Impact de la mémoire des odeurs sur la réponse hédonique au cours d'une exposition répétée. Thèse de doctorat, Université de Bourgogne, Dijon.

Tung, N., \& Krowolski, N. (1998). L'argent, le gras du boeuf et le pet du mandarin. In D. ReyHulman, \& M. Boccara (Eds.), Odeurs du monde : écriture de la nuit (pp. 149-157). Paris: L'Harmattan. Ueno, Y. (1993). Cross-cultural study of odor perception in Sherpa and Japanese people. Chemical Senses, 18, 352-353.

Walk, H. A., \& Johns, E. E. (1984). Interference and facilitation in short-term memory for odors. Perception and psychophysics, 36, 508-514.

Wysocki, C. J., Pierce, J. D., \& Gilbert, A. N. (1991). Geographic, cross-cultural, and individual variation in human olfaction. In T. V. Getchell, R. L. Doty, L. M. Bartoshuk, \& J. B. Snow (Eds.), Smell and Taste in Health and Disease (pp. 287-314). New York: Raven Press. 


\section{NOTES}

1. The codability of the distractors did not differ enough to be informative on the link between codability and recognition memory.

\section{ABSTRACTS}

We investigated the relationship between odor codability and odor memory representation in three cultural groups: French, American, and Vietnamese. In a first experiment, we asked participants from the three cultures to identify twice a set of 40 common odorants. From this task, we computed the codability of each of the 40 odorants. In a second experiment, we asked another group of participants from each culture to perform a yes/no recognition task on the same set of odorants. Results from Experiment 1 suggest that odor codability (1) is a meaningful dimension because some odors are more codable than others within a culture, (2) is equivalently measurable by several inter- and intrapersonal agreement indices, and (3) varies between cultures as a function of both the olfactory environment and language structure. Results from Experiment 2 show that the French codability scores predict recognition memory performance in all three cultures but that the American and Vietnamese codability scores predict none of the recognition performances.

Nous avons étudié la relation entre la codabilité des odeurs et leur représentation en mémoire dans trois groupes culturels, français, américain et vietnamien. Dans une première expérience, nous avons demandé à des participants des trois cultures d'identifier par deux fois un ensemble de 40 odorants. A partir de cette tâche, nous avons calculé la codabilité de chacun des 40 odorants. Dans une deuxième expérience, nous avons demandé à un autre groupe de participants de chaque culture de réaliser une tâche de reconnaissance par oui/non sur le même ensemble d'odorants. Les résultats de l'expérience 1 suggèrent que la codabilité des odeurs (1) est une dimension pertinente car certaines odeurs sont plus codables que d'autres au sein d'une même culture, (2) peut être mesurée de manière équivalente par des indices d'accords intra et interpersonnels, et (3) varie entre les cultures en fonction de l'environnement olfactif et de la structure du langage. Les résultats de l'expérience 2 montrent que les scores de codabilité en France prédisent les performances de mémoire de reconnaissance dans les trois cultures mais que les scores aux Etats-Unis et au Vietnam n'en prédisent aucun des scores de reconnaissances.

\section{INDEX}

Keywords: codability, odors, recognition memory, cross-cultural study.

\section{AUTHORS}

\section{CHRISTELLE CHREA}

Swiss Center for Affective Sciences, 7 rue des Battoirs, 1205 Geneva, Switzerland. e mail: christelle.chrea@pse.unige.ch. 


\section{CAMILLE FERDENZI}

Centre des Sciences du Goût, UMR 51-70, 15 rue Hugues Picardet, 21000 Dijon, France DOMINIQUE VALENTIN

Centre des Sciences du Goût, UMR 51-70, 15 rue Hugues Picardet, 21000 Dijon, France , HERVÉ ABDI

The University of Texas at Dallas, 2601 North Floyd Road, Richardson, Texas 75080, USA 